\title{
Assessment of the mobility of metals in a mining-impacted coastal area (Spain, Western Mediterranean)
}

\author{
M.J. Martínez-Sánchez a , M.C. Navarro a , C. Pérez-Sirvent ${ }^{\mathrm{a}, *}$, J. Marimón ${ }^{\mathrm{a}}$, J. Vidal ${ }^{\mathrm{a}}$, \\ M.L. García-Lorenzo ${ }^{\text {a }}$ J. Bech ${ }^{\mathrm{b}}$ \\ ${ }^{a}$ Department of Agricultural Chemistry, Geology and Pedology, Faculty of Chemistry, University of Murcia, E-30071 Murcia, Spain \\ ${ }^{\mathrm{b}}$ University of Barcelona, Department of Astronomy and Meteorology, E-08028 Barcelona, Spain
}

\begin{abstract}
A study on metal mobilisation (Zn, Pb and As) from contaminated sediments in Portman Bay (SE Spain) was carried out. This area has suffered a major impact from mining activity, as millions of tons of mine tailings have been dumped into the bay over a long period, gradually filling the bay. A three-step sequential extraction procedure, modified from the BCR (Community Bureau of Reference) method, as well as selective extractions $\left(\mathrm{H}_{2} \mathrm{O}, 0.1 \mathrm{~N} \mathrm{HNO}_{3}\right.$, citrate-dithionite and $1 \mathrm{M} \mathrm{NH}_{4} \mathrm{OAc}$ after $\mathrm{H}_{2} \mathrm{O}_{2}$ attack) were applied to selected samples in order to evaluate the potential mobility of fixed metals. Acid volatile sulfides (AVS) and simultaneously extracted metals (SEM) were also determined. X-ray diffraction (XRD) and scanning electron microscopy coupled to with an energy-dispersion spectrometry (SEM-EDS) were applied to the characterization of both raw samples and the residues remaining after each extraction, providing additional information about the sediment phases carrying the metals studied. Metals associated with sediments showed different behaviour depending on the mineralogical phase they were bound to. Zn was the most labile metal, while $\mathrm{Pb}$ and As showed a lower mobility. The fraction of metals associated with jarosites presented a high stability under different physicochemical conditions, while metals associated with mineralogical phases that are undergoing supergenic alteration processes presented a high mobility. The results obtained may be useful to assess both the short and the longterm environmental impact of such disposal activities as well as supporting decisions for a future remediation of the zone.
\end{abstract}

Keywords: Contaminated sediments; Metal mobility; BCR sequential extraction procedure; Acid volatile sulfides (AVS)

\section{Introduction}

Mining and milling operations, including grinding, concentrating ores and the disposal of tailings, along with mine and mill waste waters provide obvious sources of contamination to the surface environment (Adriano, 2001). Both past and present-day mining activities may represent a current source of pollution

\footnotetext{
* Corresponding author. Tel.: +34968367449; fax: +34 968364148.

E-mail address: melita@um.es(C. Pérez-Sirvent).
}

since trace elements are introduced into the atmospheric, terrestrial and aquatic ecosystems (Moore and Luoma, 1990). The extent and degree of heavy metal contam- ination around minesmayvary depending on geochem- ical characteristics, the mineralization of tailings (Jung, 2001), physico-chemical conditions (Blowes and Jam- bor, 1990; Johnson et al., 2000) and the processes used to extract metals.

Metal polluted sites represent a potentially hazardous risk for human health and the environment. The bioavailability of contaminants is increasingly used as 
indicator of potential risk. These contaminants pose a risk to environmental and human health (Adriano et al., 2004). Metals can exist in different forms in the environment, where they may be transformed from one form into another or exist in different forms simul- taneously. The form or "chemical speciation" of metals varies widely depending on environmental conditions. Such differences in chemical speciation affect the environmental fate, bioavailability and environmental risk of the metals. Knowledge of metal's speciation can help to assess the metal retention in soil or sediments and how easily it may be released into the soil solution. A great variety of extractive reagents which provide information about the strength of binding between metal and soil/sediment fractions, and hence on its potential mobility and bioavailability (Tessier et al., 1979; Kersten and Förstner, 1986; Ure et al., 1993) have been proposed but none has been fully recognized as a universal procedure applicable to all types of soils or sediments (Sheppard and Stephenson, 1997). This is a difficulty that can even lead to erroneous diagnosis in soils or sediments. The study of potential mobility involves summing up all reactions that are capable of mobilising metals (Vidal et al., 2004). With regards to the environmental risk assessment, the worst case describes "natural conditions" that lead to the highest metal release possible intheenvironment(Thömingand Calmano, 1998).

The use of selective extractions, both sequential and simple, that simulate different environmental conditions may have general applications in cases similar to Portman Bay (Fig. 1), which is situated close to the mining region of La Unión (SE Spain). The entire area around the bay was subject to mining from thetime of the Roman Empire to 1991, when the activity ceased. Since 1957, the wastes from mining operations were discharged directly into the sea in the inner part of the bay, while later on, they were also discharged further out to sea. From Lavadero Roberto (one of the biggest flotation plants in the world, which treated about 1000 tonnes/day), steriles were discharged by pipe directly into the western part of the bay, from where currents washed them towards the shore. During its working life, Lavadero Roberto discharged 57 million tonnes of steriles, made up of clay, quartz, siderite, magnetite, and the remains of sphalerite, pyrite and galena, togetherwithmetals andresidues of the chemical reagents used in floatation. As a result, the whole of the

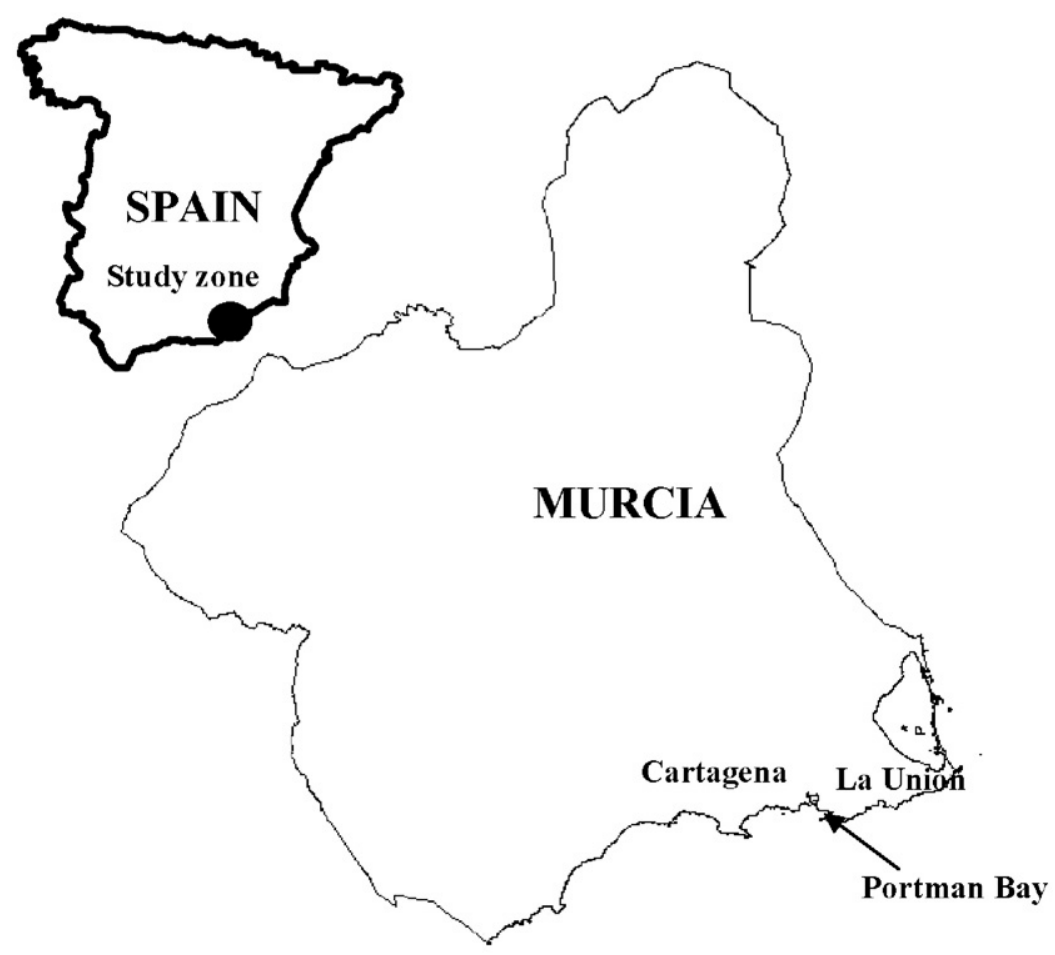

\section{Mediterranean Sea}

Fig. 1. Location map of Portman Bay. 


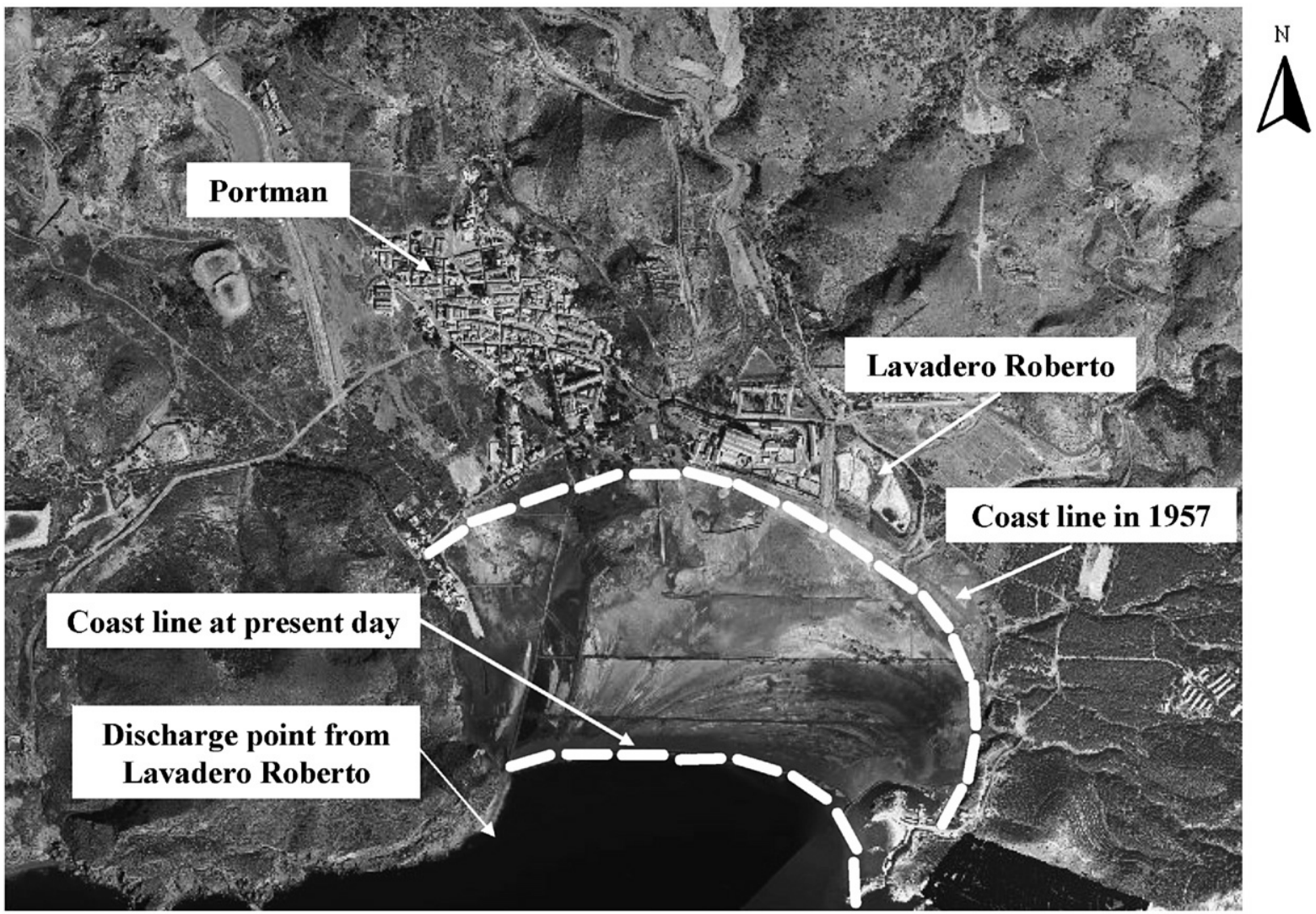

Fig. 2. Aerial view of Portman Bay. Coast lines in 1957 and at present day are indicated as well as the discharge point from Lavadero Roberto. The sediments that have filled up the bay can be seen between both coastlines.

bay has filled up with wastes (Fig. 2) which also extend into the Mediterranean itself (CEDEX, 1994). Previous studies carried out in the bay have pointed to lead, zinc, cadmium and arsenic as being the principal contami- nants. Although a certain degree of equilibrium has been reached since the discharges stopped in the 1990 's, the sediments are still subjected to marine dynamics (especially those nearest the open sea) and to the rainfall effects, runoff and other discharged wastes, not to mention activities designed to recover the bay. All these factors affect the state or form of the metals contained in the sediments and, therefore, their mobility and bioavailability (Furness and Rainbow, 1990). At present, faced with the opportunity of rehabilitating the site, public opinion is pressing for the recovery of the whole surrounding area; and one of the proposal is that the sediments should be excavated and transported else- where, so that the "original conditions" can be regained. Since bioavailability and toxicity of sediment-associated metals are governed by sitespecific factors including sediment properties, the redox potential, the chemistry of pore-water, overlying water and by the physiology and fauna's feeding behaviour, studies that provide informa- tion on metals behaviour in these sediments will help to take the correct decision, and to make processes for the zone recovery (MarínGuirao et al., 2005).

The aim of this study was to evaluate the natural and potential mobility of As, $\mathrm{Pb}$ and $\mathrm{Zn}$ from the sediments of Portman Bay as a preliminary step to analyse the risk of metal mobilisation in relation to possible changes in the use of this area. For this purpose, a number of samples considered representative with regards to the mineralogy, texture and $\mathrm{pH}$ range were selected and simple sequential procedures were applied to assess the real mobility of metals taking into account the characteristics of these sediments.

\section{Materials and methods}

Portman Bay lies on the Mediterranean coast of the Autonomous Community of Murcia between Cabo de Palos and Cartagena. The annual average temperature is $17^{\circ} \mathrm{C}$, and precipitation does not exceed $300 \mathrm{~mm}$, with occasional torrential rainfall which frequently occurs in 
the period between the end of summer and autumn. Wind is an almost constant atmospheric phenomenon in thelittoralzone.

The study has been focused on $6 \mathrm{~km}^{2}$ area. A total of 18 sampling stations were selected at intervals of at least 300 $\mathrm{m}$. Samples were taken in profiles from the sampling points in the bay at different depths depend- ing on the phreatic layer, resulting in 80 samples. After the study of mineralogical composition and total metal contents, a cluster analysis was made to determine if the data obtained could be related significantly and so be used to divide the samples into groups. Then, assigning to each sample the variable of the group obtained by the cluster analysis, a discriminant analysis was applied to show the affinity of samples with one or more groups. Four samples were selected as represen- tative of the different types of materials present in Portman Bay.

Solid samples were air dried and sieved to $\mathrm{b} 2 \mathrm{~mm}$ for general analytical determinations. The $\mathrm{pH}$ was deter- mined in a 1:5 suspension of soil in pure water. Grain size analysis was performed after dispersion of the fine soil and by combining extraction by Robinson pipette and sieving.

To determine the total metal content ( $\mathrm{Pb}, \mathrm{Zn}$, and $\mathrm{As}$ ), air dried and sieved samples were first ground to a fine powder using an agate ball mill and then $100 \mathrm{mg}$ was placed in Teflon vessels to which $5 \mathrm{ml}$ of concentrated HF solution, $200 \mu \mathrm{l}$ of concentrated $\mathrm{HNO}_{3}$ solution and $5 \mathrm{ml}$ of water were added. When digestion was complete (15 minat 1000 Wina MilestoneETHOSPLUS microwave), the sample was transferred to a volumetric flask andbrought to $50 \mathrm{ml}$. The $\mathrm{Zn}$ content was determined by flame atomic absorption spectrometry (FAAS) using a Perkin-Elmer 1100B Atomic Absorption Spectropho- tometer and the $\mathrm{Pb}$ content by electrothermal atomiza- tion atomic absorption spectrometry (ETAAS) using an Unicam 929 AASpectrometer. Arsenic was analysed by atomic fluorescence spectrometry using an automated continuous flow hydride generation (HG-AFS) spec- trometer (PSA Millenium Excalibur 10055). The reli- ability of the results was verified through the analysis of a standard reference material (SRM 2711 Montana Soil). Spikes, duplicates and reagent blanks were also used as a part of our quality assurance/quality control.

The sequential extraction used was conducted according to the modified BCR scheme proposed by Sutherland and Tack (2002). Four operationally defined fractions were identified as follows.

1. Acidextractable:1galiquotwasshakenfor 16 hat $22 \pm 5^{\circ} \mathrm{C}$ with $40 \mathrm{ml} 0.1$ Macetic acid. The extract was separated from the solid residue by centrifuga- tion at 3000 rpm for 20 min.

2. Reducible: to the step 1 residue, $40 \mathrm{ml} 0.5 \mathrm{M}$ $\mathrm{NH}_{2} \mathrm{OH} \cdot \mathrm{HCl}(\mathrm{pH} 1.5)$ were added, shaking for $16 \mathrm{~h}$ at $22 \pm 5$ ${ }^{\circ} \mathrm{C}$. Theextract wascentrifugedasperstep 1.

3. Oxidisable: to the step 2 residue $10 \mathrm{ml} \mathrm{H}_{2} \mathrm{O}_{2}$ was added and the $\mathrm{pH}$ was adjusted to $2-3$, keeping it for $1 \mathrm{~h}$ at room temperature, then heated at $85 \pm 2{ }^{\circ} \mathrm{C}$ for $1 \mathrm{~h}$; a further $10 \mathrm{ml}$ $\mathrm{H}_{2} \mathrm{O}_{2}$ was added and then heated at $85 \pm 2{ }^{\circ} \mathrm{C}$ for $1 \mathrm{~h}$; finally, $50 \mathrm{ml} 1 \mathrm{M}$ ammonium acetate ( $\mathrm{pH} 2$ ) were added and shaken for $16 \mathrm{hat} 22 \pm 5{ }^{\circ} \mathrm{C}$. The extract was centrifugedas per step 1 .

4. Residual: to the step 3 residue, $3 \mathrm{ml}$ distilled $\mathrm{H}_{2} \mathrm{O}$, $7.5 \mathrm{ml} 6 \mathrm{M} \mathrm{HCl}$, and $2.5 \mathrm{ml}$ concentrated $\mathrm{HNO}_{3}$ solution were added; leaving overnight at $20{ }^{\circ} \mathrm{C}$ before boiling under reflux for $2 \mathrm{~h}$, cooling and filtering. Selective chemical extractions, in water (1:5 extract), acidic medium (1 $\mathrm{g}$ of solid in $50 \mathrm{ml} 0.1 \mathrm{~N} \mathrm{HNO}_{3}$ ), complexing-reducing medium (Mehra and Jackson, 1960) and oxidising medium (step 3, Sutherland and Tack, 2002), were carried out in the samples to determine soluble fraction of the metals. The metal content of all the fractions was determined by FAAS or ETAAS, depending on the concentration of analyte in each extractant, while As was determined by HG-AFS.

The mineralogical composition of the residues remaining after each extraction stage was studied by X-ray diffraction (XRD) and compared with that of the raw sample, and thus additional data on the extraction processes were obtained. For this purpose a Philips PW3040 diffractometer with Cu$\mathrm{K} \alpha$ was used. The powder diffraction file (PDF2) database was used for peak identification, taking into account that the deter- mination of minerals from soils using the mentioned XRD analysis is not accurate below a limit value of $5 \%$ of the total weight in a sample (depending on the crystallinity of individual minerals). As a complemen- tary technique, samples were observed by using a JEOL 6100 scanning electron microscope equipped with an Oxford ISIS energy-dispersion spectrometer system.

A method for the determination of acid volatile sulfides (AVS) in sediments, using a common elemental analyser with thermal conductivity detector, was used (Fiedler et al., 1999). A mixture of $\mathrm{Sn}$ and $\mathrm{V}_{2} \mathrm{O}_{5}$ for pyrolysis and combustion to determine total sulfur (TS), and non-volatile sulfur(NVS) was used after acidic attack with $2 \mathrm{M} \mathrm{HCl}$. AVS was calculated as the difference between TS and NVS. The metals extracted in the acidic attack were determined as described previously. 


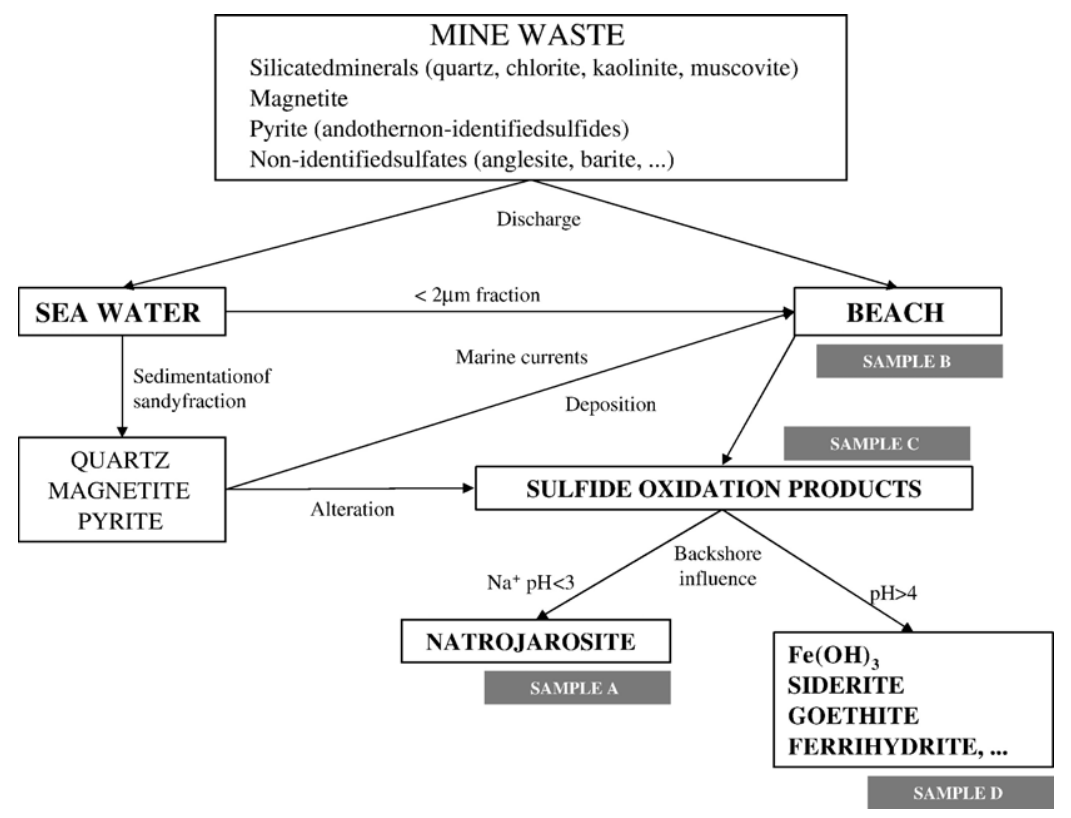

Fig.3.Generalscheme of the differentprocessesthat studied materials haveundergone.

All glass and plastic ware were cleaned by soaking in $10 \%$ $\mathrm{HNO}_{3}(\mathrm{v} / \mathrm{v})$ for $12 \mathrm{~h}$, followed by soaking and rinsing with deionised water. All of the chemicals used in the experiment were of analytical-reagent grade or better.

\section{Results and discussion}

On the one hand, the sediments studied are result of sedimentation of the residues discharged into the sea and affected by the circulating currents of the bay. On the other hand, direct contributions blown by the wind or discharged from the washer directly onto the beach (Fig. 3). The steriles discharged into the sea have undergone a sorting process, whereby the finest fractions have been lost, while the sand fraction remains. As a result of the currents in the bay and of the wind, this fraction slowly filled the bay and formed the most superficial layer, which is principally composed of black medium-fine sand. The residues directly discharged onto the beach are composed of finer materials. The sediments of the bay are stratified into alternating layers of sandandclay, whichresultsindifferentconditions of permeability. This, in turn, may give rise to different zones of aeration in which the sediments undergo supergenic alteration, involving the oxidation of pyrite and formation of iron oxides and jarosites. The iron oxides impart a yellowish brown colouration and form crusts, sometimes very hard and reaching $10-15 \mathrm{~cm}$ in thickness. These crusts coincide with the phreatic levels, below which, the conditions cease to being oxidised and become reduced and the colour changing to black or grey. Supergenic alteration takes place in otherplaces in Murcia, like Mazarrón (García Rizo et al., 1999) and Cabezo Rajao (Navarro, 2004); however, the presence of chloride and sodium due to backshore influence makes supergenic alteration products here unusual.

Table 1 shows the maximum, minimum, mean and standard deviation of the percentage of sand, $\mathrm{pH}$ values and total metal content in all the samples studied. The materials studied showed great heterogeneity in their particle size distribution (PSD), with a wide range in the percentage of sand (10-90\%, with a mean of $59 \%)$. The particle size distribution defines the origin of the sediment, fine and coarse textures corresponding to unwashed and washed steriles, respectively. The $\mathrm{pH}$ of the samples runs from acidic (min. 2.8) to slightly acidic (max.6.3), due to the influence of the sea waterin some

Table1

Sand percentage, $\mathrm{pH}$ and total metal content of the sediments sampled $(N=80)$

\begin{tabular}{|c|c|c|c|c|c|c|c|}
\hline & \multirow{2}{*}{$\begin{array}{l}\text { Sand } \\
\text { (\%) }\end{array}$} & \multicolumn{6}{|c|}{ pH Totalcontent(mgkg $\left.{ }^{-1}\right)$} \\
\hline & & & Zn & $\mathrm{Pb}$ & $\mathrm{Cd}$ & $\mathrm{Cu}$ & As \\
\hline Maximum & 95 & 6.3 & 26,873 & 19,587 & 21.8 & 308 & 6620 \\
\hline Mean & 59 & 4.4 & 7793 & 6006 & 5.9 & 75 & 1708 \\
\hline Minimum & 10 & 2.8 & 251 & 822 & 0.2 & 15 & 77 \\
\hline \multicolumn{2}{|c|}{ Standarddeviation 23.81 .3} & & 8531 & 4645 & 6.6 & 60 & 1336 \\
\hline
\end{tabular}


Table2

$\mathrm{pH}$, total metal content and particle size distribution of the four selected sediments

\begin{tabular}{|c|c|c|c|c|}
\hline & Sample A & Sample B & Sample C & Sample D \\
\hline Depth (cm) & $10-30$ & N27 & $4-10$ & $18-26$ \\
\hline $\mathrm{pH}(1: 5)$ & 3.83 & 5.62 & 2.82 & 4.64 \\
\hline $\mathrm{Zn}\left(\mathrm{mgkg}^{-1}\right)$ & 827 & 15280 & 1405 & 7974 \\
\hline $\begin{array}{l}\mathrm{Pb}\left(\mathrm{mgkg}^{-1}\right) \\
\mathrm{As}\left(\mathrm{mgkg}^{-1}\right)\end{array}$ & $\begin{array}{l}7265 \\
1676\end{array}$ & $\begin{array}{l}1837 \\
1734\end{array}$ & $\begin{array}{l}4077 \\
2405\end{array}$ & $\begin{array}{l}3120 \\
1737\end{array}$ \\
\hline $\mathrm{Cd}\left(\mathrm{mg} \mathrm{kg}^{-1}\right)$ & 0.3 & 17.5 & 0.2 & 11.3 \\
\hline $\mathrm{Cu}\left(\mathrm{mg} \mathrm{kg}^{-1}\right)$ & 18 & 75 & 34 & 96 \\
\hline \multicolumn{5}{|l|}{ Particlesize $(\mu \mathrm{m})$} \\
\hline b2(\%) & 65 & 10 & 10 & 10 \\
\hline 2-20(\%) & 10 & 10 & 30 & 0 \\
\hline 20-50 (\%) & 6 & 1 & 6 & 1 \\
\hline 50-100(\%) & 4 & 3 & 11 & 2 \\
\hline 100-250(\%) & 8 & 49 & 37 & 71 \\
\hline $250-500(\%)$ & 5 & 23 & 5 & 16 \\
\hline 500-1000 (\%) & 1 & 3 & 1 & 0 \\
\hline $1000-2000(\%)$ & 0 & 2 & 0 & 0 \\
\hline
\end{tabular}

of the samples (which raises the $\mathrm{pH}$ ). The metal content reveals the heterogeneous nature of the materials, and great differences betweenthemaximumandminimum

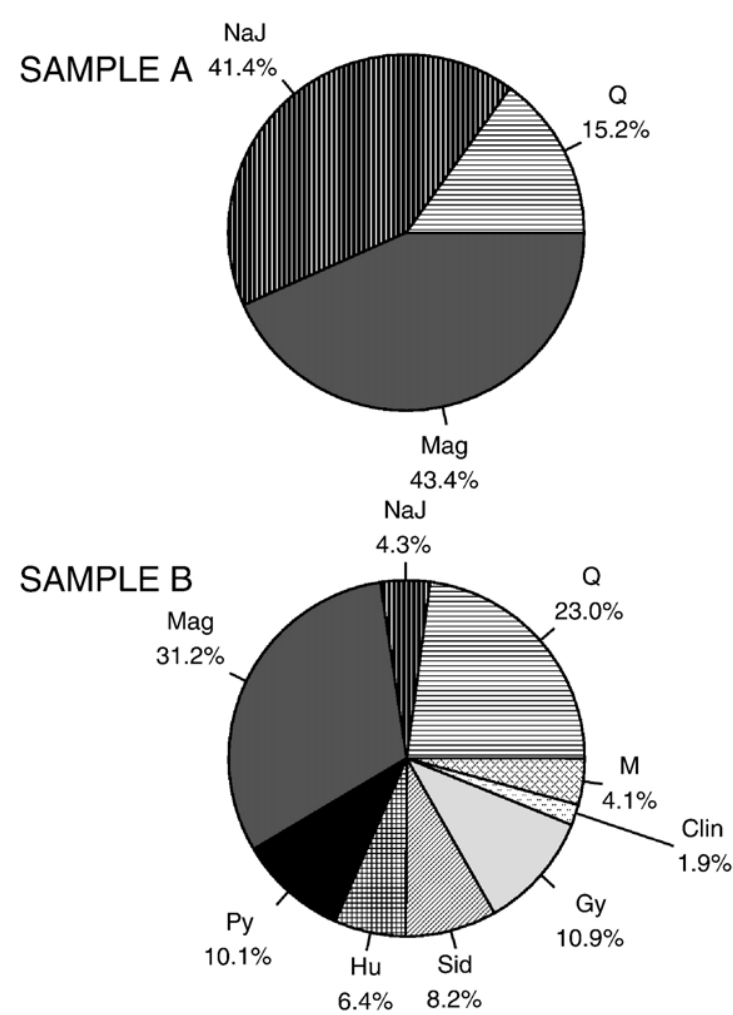

values could be observed. The milling of the mined materials and the differential floatation processes they were subjected to separate the metallic sulfides have led to differences in the texture and metal concentrations between the different materials.

The four representative samples were selected from different depths and showed differences in pH, PSD and metal content(Table 2). The most superficial samples (A and C) showed the lowest $\mathrm{pH}$ values. Sample Ahadhigh percentage of fine fraction. Samples B and $\mathrm{D}$ showed higher fine sand content, while $\mathrm{C}$ showed $30 \%$ fine silt and 37\% fine sand. With regards to the metal content, sample B showed the highest Zn content (15280 $\mathrm{mg} \mathrm{kg}^{-1}$ ), while sample A presented the highest $\mathrm{Pb}$ content $\left(7265 \mathrm{mg} \mathrm{kg}^{-1}\right.$ ). The As content was more homogeneous in the samples, while $\mathrm{Cd}$ and $\mathrm{Cu}$ were present in lower concentrations than the other metals mentioned. The mineralogical composition of each sample is represented in Fig. 4, which reflects the different degrees of alteration that these materials have undergone or are undergoing as a function of environmental conditions, especially the acidity of the medium and
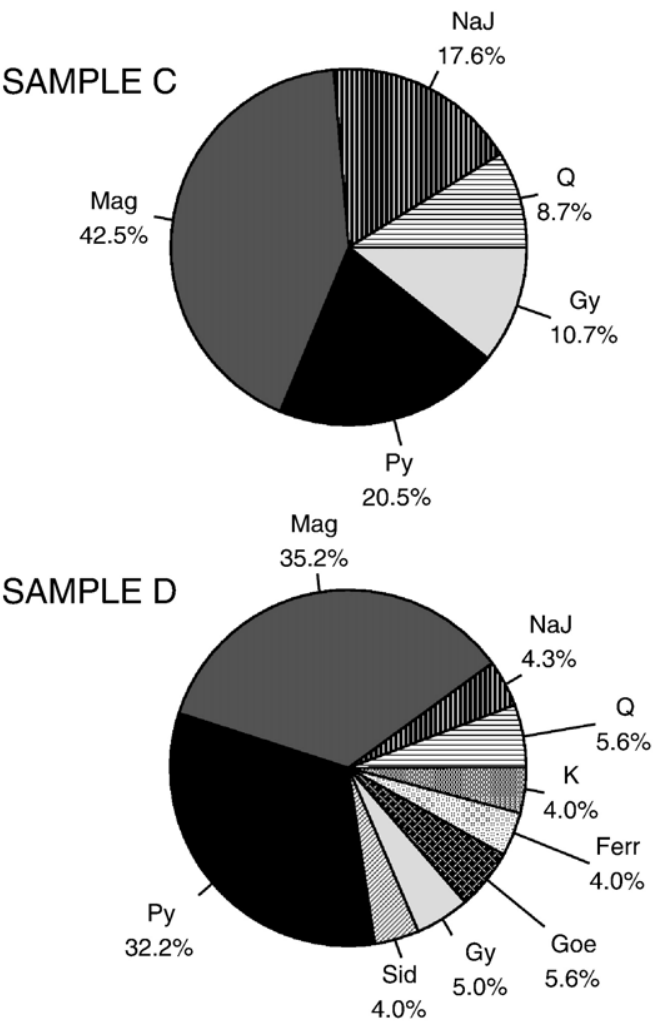

Q: quartz; NaJ: natrojarosite; Mag: magnetite; Py: pyrite; Gy: gypsum; Sid: siderite; Clin: clinochlore; M: muscovite; Hu: huntite; K: kaolinite; Ferr: ferrihydrite; Goe: goethite

Fig. 4. Mineralogical composition of the four selected samples. 
the redox potential. The joint presence of phases such as sulfides demonstrates that the supergenic alteration process in these materials maybeon-going.

The concentration of metals in each of the fractions after each of the sequential extraction phases, the con- centration in the residual fraction, together with con- centrations obtained in each of the simple extractions and the total contents are shown in Table 3. There were differences in metal concentrations between samples. $\mathrm{Pb}$ and As were below the detection limit in the weaker extractants, while Zn seemed to be more soluble. In general, the sum of metal concentration from the four sequential extraction steps was between $\pm 10 \%$ of total concentrations determined after microwave digestion.

The extraction percentages for each sample in each of the extractions are shown in Fig. 5. The acid-extractable fraction contains the metals which are precipitated or co- precipitated with carbonate, which can be an important adsorbent for many metals when organic matter and Fe- Mn oxides are less abundant in the aquatic system. The reducible fractions mainly consist of manganese and iron oxyhydroxides, which scavenge metals in the form of coatings on mineral surfaces or as fine discrete particles by one or a combination of the following mechanisms: co- precipitation, adsorption,surfacecomplexformation, ion exchange and penetration of the lattice (Filgueiras et al., 2002). The oxidisable fraction includes trace metals associated with various forms of organic material, such as living organisms, detritus or coatings on mineral particles, by means of complexation or bioaccumulation processes. Metallic pollutants associated with oxidisable phases are assumed to remain in the soil for longer periods but may be mobilised by decomposition processes. Metals bound to sulfides might be extracted during this step. Generally, metals in the acid-soluble fractions are considered readily and potentially bioavailable, while the reducible and oxidisable fractionsarerelativelystableundernormalsoil conditions.

With regards to simple extractions, trace elements extracted by water are relatively labile and thus may be potentially bioavailable. This fraction contains the water-soluble species made up of free ions complexed with soluble organic matter and other constituents. It contains the most mobile and potentially the most available metal and metalloid species. The extraction with $0.1 \mathrm{~N} \mathrm{HNO}_{3}$, is a modification of $1 \mathrm{M} \mathrm{HNO}_{3}$ extraction, whereby metals complexed with organic matter, adsorbed or co-precipitated to oxyhydroxides, carbonated or sulfides can be solubilised (Soon and Abboud, 1993). In this case, the extraction may be useful for estimating maximum potential metal mobili- sation in the face of changing environmental conditions (Ure and Davidson, 2002). Extraction in a complexing- reducing medium containing citrate and dithionite partially mobilises hematite, goethite, lepidocrocite, ferrihydrite, non-crystallised iron oxides and organic complexes of iron and aluminium (Mehra and Jackson, 1960), permitting the free, non-silicated iron and associated metals to be evaluated (Ross and Wang, 1993). The oxidant extraction was useful for simulating the final steps of the alteration process to which the studied materials are subjected in natural conditions.

\subsection{Sample A}

The mineralogical composition of sample $\mathrm{A}$ is basically of natrojarosite, magnetite and quartz (Fig. 4), although amorphous phases like iron oxyhydroxides undetected by XRD may also be present. Sulfides were also not detected, but again this does

Table3

$\mathrm{Zn}, \mathrm{Pb}$ and As concentrations $\left(\mathrm{mg} \mathrm{kg}^{-1}\right)$ in the different steps of sequential and simple extraction

\begin{tabular}{|c|c|c|c|c|c|c|c|c|c|c|c|c|}
\hline & \multicolumn{4}{|c|}{$\mathrm{Zn}\left(\mathrm{mg} \mathrm{kg}^{-1}\right)$} & \multicolumn{4}{|c|}{$\mathrm{Pb}\left(\mathrm{mg} \mathrm{kg}^{-1}\right)$} & \multicolumn{4}{|c|}{$\mathrm{As}\left(\mathrm{mg} \mathrm{kg}^{-1}\right)$} \\
\hline & A & $\mathrm{B}$ & $\mathrm{C}$ & $\mathrm{D}$ & A & B & $\mathrm{C}$ & $\mathrm{D}$ & A & B & $\mathrm{C}$ & $\mathrm{D}$ \\
\hline Acid-extractable & 40 & 5026 & 445 & 3301 & - & 149 & - & - & - & - & 464 & - \\
\hline Reducible & 19 & 1800 & 44 & 324 & 84 & 718 & 170 & 655 & 16 & 104 & 187 & 102 \\
\hline Oxidisable & 24 & 2290 & 297 & 1653 & 57 & 122 & 201 & 277 & 130 & 347 & 724 & 1042 \\
\hline Residual & 691 & 5794 & 563 & 2767 & 7049 & 666 & 3357 & 2074 & 1491 & 1300 & 986 & 694 \\
\hline Overall & 774 & 14190 & 1349 & 8045 & 7190 & 1655 & 3728 & 3006 & 1637 & 1751 & 2361 & 1838 \\
\hline Water & 7 & 16 & 83 & 70 & - & - & 2 & 12 & - & - & - & - \\
\hline $\mathrm{HNO}_{3}$ & 18 & 1442 & 56 & 944 & 73 & 221 & 80 & 551 & 5 & 4 & 243 & 22 \\
\hline Citr-dith & 188 & 238 & 252 & 1017 & 46 & 18 & 67 & 6 & 419 & 50 & 543 & 273 \\
\hline Ox med & 22 & 3725 & 115 & 2139 & 27 & 1100 & 44 & 1366 & 54 & 369 & 596 & 617 \\
\hline Total(mgkg $\left.{ }^{-1}\right)$ & 827 & 15283 & 1405 & 7974 & 7265 & 1837 & 4077 & 3120 & 1676 & 1734 & 2405 & 1737 \\
\hline
\end{tabular}

The sum of three steps of BCR and residual is also included as well as total content determined after microwave digestion.

(-): Below detection limit; Water: water extraction (1:5, solid:solution ratio); $\mathrm{HNO}_{3}: 0.1 \mathrm{~N} \mathrm{HNO}_{3}$ extraction; Citr-dith: citrate-dithionite extraction (Mehra and Jackson, 1960); Ox med; oxidising medium extraction (step 3, Sutherland and Tack, 2002). 

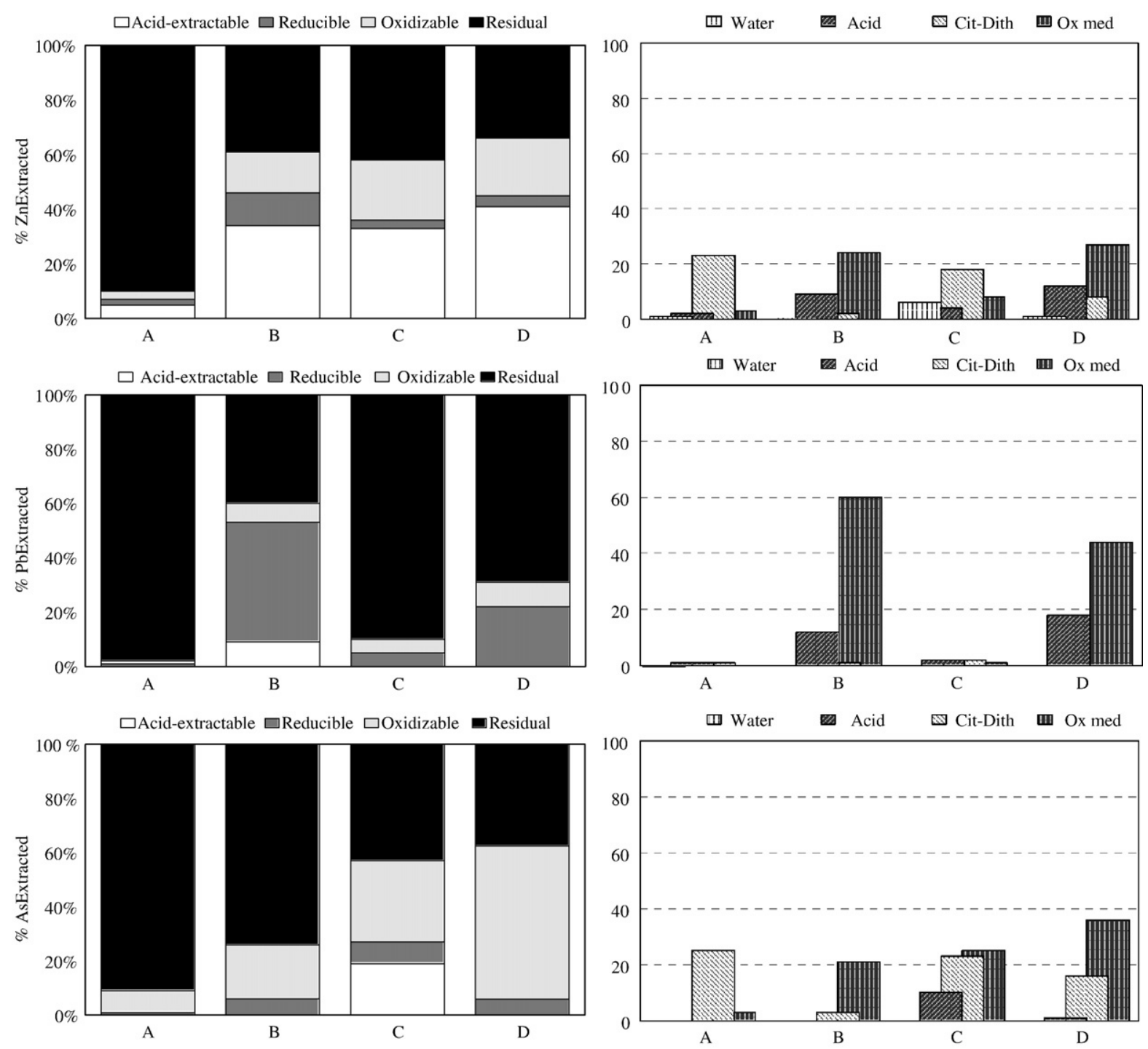

Water: water extraction (1:5, solid:solution ratio); Acid: $0.1 \mathrm{NHNO}_{3}$ extraction; Cit-dith: citrate-dithionite extraction (Mehra and Jackson, 1960); Ox med; oxidising mediumextraction (step 3, Sutherland and Tack 2002).

Fig. 5. Partitioning of metals into operationally defined fractions, (left column) sequential extraction and(right column) simpleextractions.

not exclude the possibility of their presence in small proportions.Ingeneral,noappreciabledifferences were observedin the mineralogical composition of the sample after the differentsteps ofthesequential extraction.

After the three sequential extraction steps, $\mathrm{Zn}, \mathrm{Pb}$ and As were retained in the residual fraction (Fig. 5), which indicates that they are mostly bound to the stable phases that are not attacked in the different extraction media. The extraction percentages obtained in some of the steps may have been due to the association with badly crystallised phases which were not detected by XRD, such as soluble sulfates and iron oxyhydroxides in the case of Zn and sulfides in the case of As. The stability of the jarosites in the sample in question is revealed by the SEM-EDS study. Mapping of the chemical element distribution (Fig. 6) and microanalysis of the residue after the third step of the extraction process, points to the presence of these phases after the three extractions.

With regards to the simple extractions, they were probably more aggressive in some cases than the corresponding sequential extractions. The $\mathrm{Zn}$ soluble in complexing-reducing medium exceeded $20 \%$ (Fig. 5), which is much more than was solubilised in the three BCR (Community Bureau of Reference) steps. In this medium, Fe and Mn oxyhydroxides were attacked, as wasasmallportionof thejarosites oflowcrystallinity, 

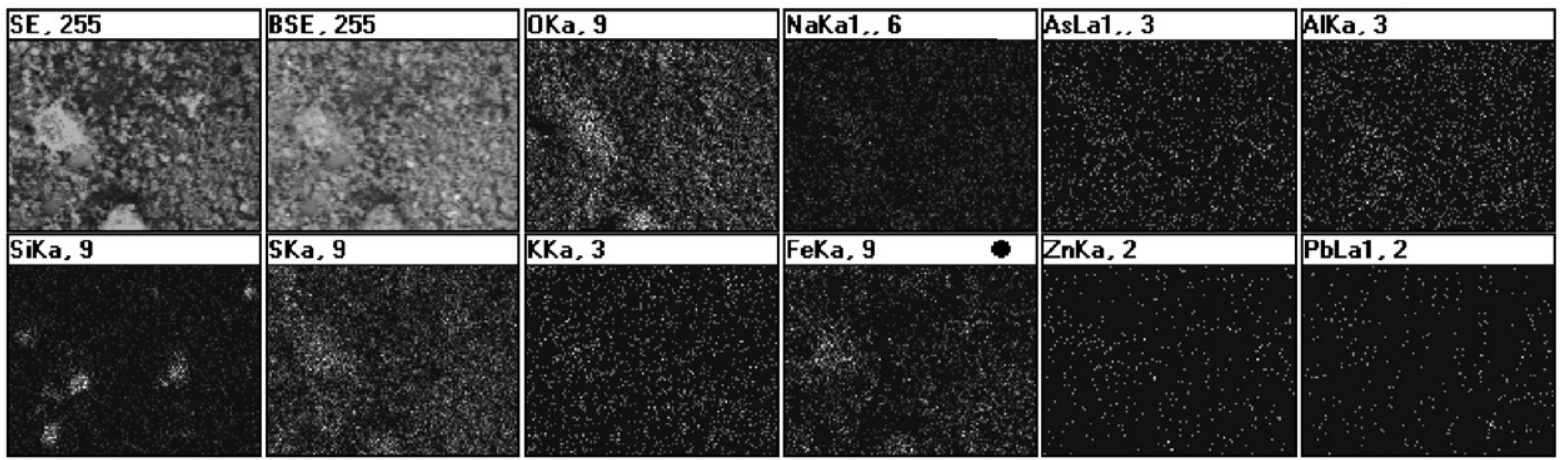

Fig. 6. Mapping of the chemical element distribution of sample A after third BCR step obtained by SEM-EDS.

because, besides being a reducing medium, it also contained citrate, which acted as a metal complexing agent. The percentage of $\mathrm{Pb}$ extracted in all the simple extractions was always zero, which was also the case with BCR (Fig. 5). Arsenic behaved similarly to $\mathrm{Zn}$ in the simple extractions, when it was mainly solubilised in the complexing-reducing medium. The tendency of both metals was also similar in the sequential extractions, so that they must be associated with the same phases as well as with each other.

\subsection{Sample B}

Sample B had a more complex mineralogical compo- sition since, together with the phases themselves that may appear in the steriles left after the mineral extraction process (quartz, sulfides, magnetite), others, such as natrojarosite, gypsum and huntite, which are the consequence of supergenic alteration processes and which may incorporate metalsintheir structures, werealsoevident(Fig.4).

The metals in this sample seemed to be more spread among the different phases. After the first BCR step in acid medium, $34 \%$ of the Zn, possibly bound to gypsum and carbonates, was extracted (Fig. 5). In reducing medium, $12 \% \mathrm{Zn}$ was extracted, this time associated with the less crystallised jarosites and Fe and Mn oxyhydr- oxides, while in the oxidising medium another $15 \%$ was extracted, the remaining $39 \%$ associated with the residual fraction. The $\mathrm{Pb}$ in this sample was principally dissolved in the reducible fraction (44\%), compared with 9\% in the acid fraction (associated with carbonates) and 7\% in the oxidisable fraction. The As extracted in the oxidisable fraction (20\%) suggested its association with sulfides, although it could also have been associated with the jarosites, which, being of a low degree of crystallinity, would havereleasedthe As afterbeing attacked.

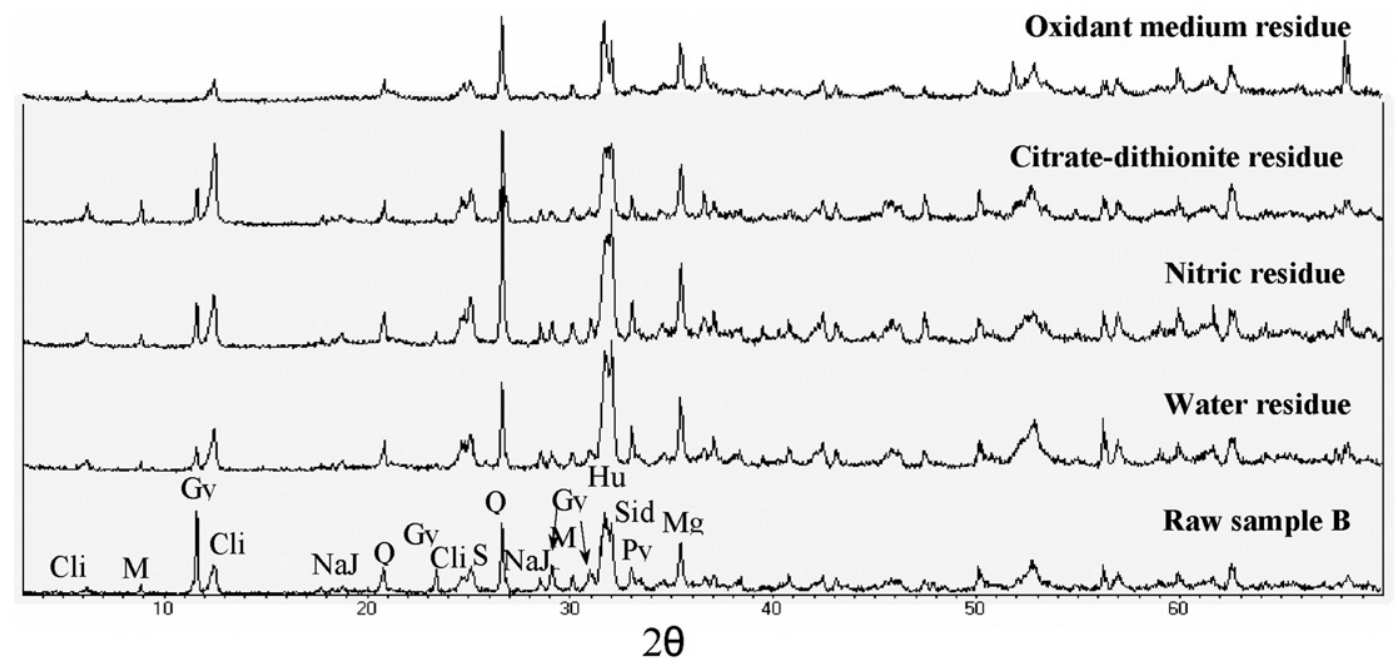

Fig. 7. X-ray diffractograms of sample B (raw sample and residues after the different selective extractions). After $0.1 \mathrm{NHNO}_{3}$ extraction, gypsum is lower if compared with raw sample as is pyrite after extraction in oxidant medium. 


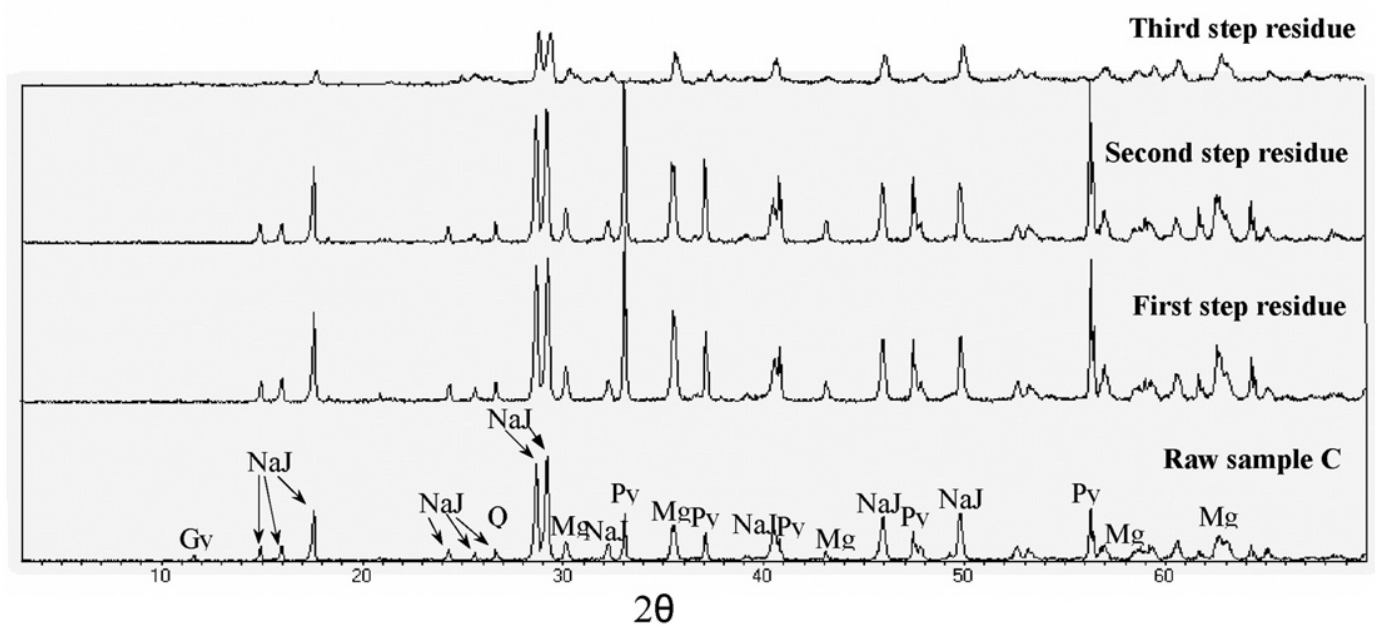

Fig.8.X-ray diffractograms of sampleC(raw sampleandresidues aftersequential extraction). Afterfirststep gypsumislowerifcompared withraw samplejustlikelow crystalline natrojarosite afterthirdstep. Pyritedisappears afterthethird step of the extraction.

With regards to the simple extraction carried out, Zn was mainly extracted in the acid medium as a consequence of the gypsum, siderite and soluble sulfates being attacked (Fig. 7). In oxidising medium, the percentage extracted was greater (24\%) than in the other media used, due to the washing of the previous phases and the attack on the sphalerite. The $\mathrm{Pb}$ was also partially attacked in the acid medium due to the attack on the gypsum, siderite and soluble sulfates, and a high percentage in oxidising medium, which may indicate the presence of phases such as galena or cerusite (not detected by XRD), which are more stable in the face of the above attacks. Arsenic is mainly extracted in oxidising medium, similarly to $\mathrm{Zn}$; however, none was extracted in the oxidising medium so that it is not associated with gypsum or carbonates, but to sulfides, which were attacked in this medium (Fig. 7).

\subsection{Sample $C$}

This sample was composed of quartz, magnetite, pyrite and the supergenic alteration products, jarosite and gypsum (Fig. 4). Galena, sphalerite and soluble sulfates may also have been present, although they were not detected by XRD.

In the sequential extraction, 33\% of the zinc was extracted in the acid step and $22 \%$ in the oxidising step, the low percentage extracted in the reducing step reflects the association of the metal with hydrated sulfates, gypsum, jarosites and sulfides (Fig. 8). Practically all the lead were retained in the residual fraction (Fig. 5), since very low percentages were extracted in the three steps of the extraction process. Arsenic behaved similarly to $\mathrm{Zn}$, emphasising their close association. Simple extractions produced very similar results for all the metals concerned. The water- extracted Zn pointed to the presence of soluble phases; the percentage of $\mathrm{Pb}$ extracted was low in all the extractions, as it was in the sequential extraction steps, underlining the stability of the phases it is associated to. Although As showed similar behaviour to $\mathrm{Zn}$, it was not soluble in water, but was soluble in media where the Fe and Mn phases, to which it is associated, could be attacked.

Table4

Simultaneously extracted metals, Acid volatile sulfides and SEM/AVS ratio in the four selected samples

\begin{tabular}{lcllrrrr}
\hline & $\begin{array}{l}\text { Zn-SEM } \\
(\mu \mathrm{mol} / \mathrm{g})\end{array}$ & $\begin{array}{l}\text { Cd-SEM } \\
(\mu \mathrm{mol} / \mathrm{g})\end{array}$ & $\begin{array}{l}\text { Cu-SEM } \\
(\mu \mathrm{mol} / \mathrm{g})\end{array}$ & $\begin{array}{l}\text { Pb-SEM } \\
(\mu \mathrm{mol} / \mathrm{g})\end{array}$ & $\begin{array}{l}\Sigma \text { SSEM } \\
(\mu \mathrm{mol} / \mathrm{g})\end{array}$ & \multicolumn{1}{l}{$\begin{array}{l}\text { AVS } \\
(\mu \mathrm{mol} / \mathrm{g})\end{array}$} \\
\hline Sample A & 0.92 & 0.00 & 0.14 & 14.89 & 15.96 & 72.1 & 0.22 \\
SampleB & 142.37 & 0.15 & 0.77 & 0.66 & 143.95 & 47.2 & 3.05 \\
SampleC & 10.44 & 0.00 & 0.36 & 5.32 & 16.12 & 510.7 & 0.03 \\
SampleD & 74.96 & 0.10 & 1.07 & 0.15 & 76.28 & 507.7 \\
\hline
\end{tabular}




\subsection{Sample D}

The mineralogical composition of this sample reflected its proximity to the phreatic layer due to the presence of goethite and ferrihydrite, phases that play an important role in the metal adsorption/desorption processes. It also contained magnetite, natrojarosite, siderite, quartz and kaolinite(Fig.4).

Using sequential extraction, the first attack extracted $41 \%$ of the zinc, while the oxidising step extracted $21 \%$. The release of $22 \%$ of the $\mathrm{Pb}$ in the reducing step pointed to its possible association with phases such as goethite and ferrihydrite. Most of the As was extracted during the oxidising step, reflecting its association with the sulfides. With regards to the simple extractions, the highest percentages of the three metals were extracted in the oxidising medium, particularly lead (43\%). Of note was the quantity of acidsoluble $\mathrm{Pb}$ as a consequence of the attack on the siderite. The As was also mobilised in the complexing-reducing medium, because in the presence of citrate, which acts as complexing agent, its retention capacity on phases such as goethite and ferrihydrite diminishes. However, phases such as pyrite, magnetite and the silicates were not attacked.

\subsection{Acid volatile sulfides and simultaneously extracted metals}

The AVS is a procedurally defined fraction contain- ing the relatively labile $\mathrm{Fe}$ and $\mathrm{Mn}$ monosulfides as the dominant component (Morse et al., 1987; Förstner, 1995). Other trace metals such as $\mathrm{Cd}, \mathrm{Cu}, \mathrm{Pb}, \mathrm{Ni}$, and $\mathrm{Zn}$ displace Fe and $\mathrm{Mn}$ from sulfide and their stronger binding with sulfide makes them unavailable for uptake by aquatic organisms (Di Toro et al., 1992). Simultaneously extracted metals (SEM), the metals extracted by the AVS extraction method, are another measure of potentially bioavailable metal concentra- tions in sediment (Yu et al., 2001). However, other binding phases with various sulfides and polysulfides, oxyhydroxides, inorganic and organic carbon are important in controlling bioavailability and may domi- nate in some sediments.

Table 4 shows the concentrations of AVS and SEM, and the SEM/AVS ratio. The concentrations of sulfur determined revealed the presence of sulfides in all the samples, despite the fact that they could not be determined by XRD in all the samples (as it was the case in sample A). However, the metals extracted in this way also arose from the attack on other phases, such as the gypsum and carbonates present in some of the samples (BandD).Ofthefoursamples, Bshowedthe lowest quantity of AVS, i.e. the lowest proportion of sulfur in the form of sulfide, but the greatest total of SEM, since, as mentioned, the metals come from the acid attack on the rest of the phases. Znand Pb showed thehighestconcentrationafter extraction with $2 \mathrm{M} \mathrm{HCl}$, which supports the presence of sphalerite and galena in the samples. The SEM/AVS ratio was 3.05 in sample B but belowunityintheotherthreesamples analysed.

\section{Conclusions}

The prevailing mineralogy was the factor that most influenced the mobility of the metals studied ( $\mathrm{Zn}, \mathrm{Pb}$ and $\mathrm{As}$ ) in these sediments. As has been demonstrated, the formation of jarosite immobilises the metals, even at low $\mathrm{pH}$ values, when this phase becomes extremely crystallised and therefore very stable. The same does not occur with the other phases, such as the carbonates, which may undergo alteration if the conditions change, especially if the $\mathrm{pH}$ falls. The presence of other phases, such as goethite or ferrihydrite, also plays an important part in surface adsorption/desorption processes. The presence of sulfides in some sediments means that they can be oxidised and release metals, as revealed by the extractions in oxidising medium and the third BCR step, especially in sample B.

In light of the results obtained, transportation of the sediments to another site would involve a change in present day conditions and the potential mobility of the associated metals. Their low water solubility (1:5 extraction, which reflects their natural mobility) points to a certain degree of instability even in present-day conditions. It should be noted that the high amount of AVSpresent in the sediments poses a serious risk if they are moved from its actual site to another one in which oxidising conditions could exist. In such a case, a huge amount of sulfuric acid could be released, with severe consequences to the environment. A far less risky alternative would seem to be the application of stabilisation and recovery measures in situ.

\section{Acknowledgements}

Funding for this project was provided by Spanish Ministerio deMedioAmbienteunderaward333/2006/ 2-1.1.

\section{References}

Adriano, D.C., 2001. Trace Elements in Terrestrial Environments: Biogeochemistry, Bioavailability and Risks of Metals, 2nd edition. SpringerVerlag. 866pp. 
Adriano, D.C., Wenzel, W.W., Vangronsveld, J., Bolan, N.S., 2004. Role of assisted natural remediation in environmental cleanup. Geoderma 122, 121142.

Blowes, D.W., Jambor, J.L., 1990. The pore-water geochemistry and mineralogy of the vadosezone of the Waite Amuletminetailings impoundment, Noranda, Quebec. Appl. Geochem. 5, 327-346.

CEDEX, 1994. (http://almeria.cedex.es/CEPYC/bibl/memo/1994/ memo.html).

Di Toro, D.M., Mahony, J.D., Hansen, D.J., Scott, K.J., Carlson, A.R., Ankley, G.T., 1992. Acid volatile sulfide predicts the acute toxicity of cadmium and nickelinsediments.Environ. Sci. Technol. 26,96-101.

Fiedler, H.D., Rubio, R., Rauret, R., Casals, I., 1999. Acid volatile sulfide determination in sediments using elemental analyzer with thermal conductivity detector. Talanta 48, 403-407.

Filgueiras, A.V., Lavilla, I., Bendicho, C., 2002. Chemical sequential extraction for metal partitioning in environmental solid samples.

J. Environ. Monit. 4, 823-857.

Förstner, U., 1995. Non-linear release of metals from aquatic sediments. In: Salomons, W., Stigliani, W.M. (Eds.), Biogeody- namics of Pollutants in Soils and Sediments. Springer, Berlin. 247-307pp.

Furness, R.W., Rainbow, P.S., 1990. Heavy Metals in the Marine Environment. CRC Press, Boca Raton, FL. 256 pp.

García Rizo, C., Martínez-Sánchez, J., Pérez-Sirvent, C., 1999. Environmental transfer of zinc in calcareous soils in zones near old mining sites withsemi-aridic climate. Chemosphere39, 209-227.

Johnson, R.H., Blowes, D.W., Robertson, W.D., Jambor, J.L., 2000. The hydrogeochemistry of the Nickel Rim mine tailings impoundment, Sudbury, Ontario. J. Contam. Hydrol. 41, 49-80.

Jung, M.C., 2001. Heavy metal contamination of soils and waters in and around the Imcheon Au-Ag mine, Korea. Appl. Geochem. 16, 1369-1375.

Kersten, M., Förstner, U., 1986. Chemical fractionation of heavy metals in anoxic estuarine and coastal sediments. Water Sci. Technol. 18, 121-130.

Marín-Guirao, L., Cesar, A., Marín, A., Lloret, J., Vita, R., 2005. Establishing the ecological quality status of soft-bottom mining- impacted coastal water bodies in the scope of the Water Framework Directive. Mar. Pollut. Bull. 50, 374-387.

Mehra, O.P., Jackson, M.L., 1960. Iron oxide removal from soils and clays by a dithionite-citrate system buffered with sodium bicarbonate. Clay Miner. Bull. 7, 317-327.

Moore, J.N., Luoma, S.N., 1990. Hazardous wastes from large-scale metal extraction. Environ. Sci. Technol. 24, 1278-1285.
Morse, J.W., Millero, F.J., Cornwell, J., Rickard, D., 1987. The chemistry of the hydrogen sulfide and iron sulfide systems in natural waters. Earth-Sci. Rev. 24,1-42.

Navarro, M.C., 2004. Movilidad y biodisponibilidad de metales pesados en el emplazamiento minero Cabezo Rajao (Murcia). Ph.D. Thesis, University of Murcia, Murcia, Spain.

Ross, G.J., Wang, C., 1993. Extractable Al, Fe, Mn and Si. In: Carter, M.R.(Ed.). Soil Sampling and Methods of Analysis. Canadian Society of Soil Science. Lewis Publishers, 823 pp.

Sheppard, M.I., Stephenson, M., 1997. Critical evaluation of selective extraction methods for soils and sediments. In: Prost, R. (Ed.), Contaminated Soils. 3rd International Conference on the Biogeo- chemistry of Trace Elements. INRA, Paris, $525 \mathrm{pp}$.

Soon, Y.K., Abboud, S., 1993. Cadmium, Chromium, Lead and Nickel. In: Carter, M. R. (Ed). Soil Sampling and Methods of Analysis. Canadian Society of Soil Science. Lewis Publishers, 823 pp.

Sutherland, R.A., Tack, F.M.G., 2002. Determination of Al, Cu, Fe, Mn, Pb and $\mathrm{Zn}$ in certified reference materials using the optimized BCR sequential extraction procedure. Anal. Chim. Acta 454, 249-257.

Tessier, A., Campbell, P.G.C., Bisson, M., 1979. Sequential extraction procedure for thespeciationofparticulatetracemetals. Anal.Chem. 51, 844-851.

Thöming, J., Calmano, W., 1998. Applicability of single and sequential extractions for assessing the potential mobility of heavy metals in highly polluted soils. Acta Hydrochim. Hydrobiol. 26, 338-343.

Ure, A.M., Davidson, C.M., 2002. Chemical speciation in soils and related materials by selective chemical extraction. In: Ure, A.M., Davison, C.M. (Eds.), Chemical Speciation in the Environment. Blackwell Science. $451 \mathrm{pp}$.

Ure, A.M., Quevauviller, P.H., Muntau, H., Griepink, B., 1993. Speciation of heavy metals in soils and sediments. An account of the improvement and harmonization of extraction techniques undertaken under the auspices of the BCR of the Commission of the European Communities. Int. J. Environ. Anal. Chem. 51, 135-151.

Vidal, J., Pérez-Sirvent, C., Martínez-Sánchez, M.J., Navarro, M.C., 2004. Origin and behaviour of heavy metals in agricultural Calcaric Fluvisols in semiarid conditions. Geoderma 121, 257-270.

Yu, K., Tsai, L., Chen, S., Ho, S., 2001. Chemical binding of heavy metals in anoxic river sediments. Water Res. 35, 4086-4094. 